\title{
Function Transformation of Government from the Low-carbon Economy Perspective: Model, Path and Integration
}

\author{
Zuojun Wang ${ }^{1,2}$, Diwan $\mathrm{Li}^{1}$, Jin $\operatorname{Tan}^{1} \&$ Yan Luo ${ }^{1}$ \\ ${ }^{1}$ School of Political Science and Public Administration, Southwest University, Chongqing, China \\ ${ }^{2}$ University of Illinois at Urbana-Champaign, Champaign, U.S.A \\ Correspondence: Zuojun Wang, School of Political Science and Public Administration, Southwest University, \\ Chongqing, China. Tel: 86-136-0835-2439. E-mail: wzj788@163.com
}

Received: October 19, 2014 Accepted: October 27, 2014 Online Published: October 29, 2014

doi:10.5539/par.v3n2p178 URL: http://dx.doi.org/10.5539/par.v3n2p178

\begin{abstract}
With the development of the world economy and the unsustainable use of resources, the environment is becoming devastating and has serious problems. In order to strengthen environmental management, it's time to develop the low-carbon economy. Government as the main body, it should transform its functions actively to promote the development of the low-carbon economy in the whole society. This article selects a new perspective that is through two dimensions "the implementation efficiency of government function" and "the extent of low-carbon marketization", and accordingly constructs four modes of the transformation of government function from the perspective of low carbon economy, that is "accomplish nothing" type, "stick in the mud" type, "paper tiger" type and "much to offer" type. Furthermore, the article discusses the transformation paths between these models and makes it system integration (M-P-I paradigm). To achieve the best transformation of government functions from low-carbon perspective, finally, this paper provides related advices and strategies for governments department.
\end{abstract}

Keywords: low-carbon economy, function transformation of government, mode construction, transformation path, systematic integration

\section{Introduction}

In recent years, with the rapid development of Chinese economics and the acceleration of social transformation, resource dependence and environment pollution are becoming more and more serious. According to the People's Daily on January 13, 2013, there were 33 cities whose air quality index (AQI) in parts of the detecting sites data over 300 among the 74 cities compared with the good air quality value of 100, which mean the air quality is seriously polluted. From the above one can come to the conclusion that "Low-carbon" is not only a high pursuit in the literal, but also an imperative aspect related to the sustainable economic growth and people's happiness.

During recent years, the country focused reforms on government systems and the strategic readjustment of economic structure. The Third Plenary Session of 18th CPC Central Committee pointed out that government should speed up the transformation of functions powerfully, deepen reforms of administration system, and innovate administrative management style, enhance its credibility and execution, and establish a law-based and service-oriented government. Therefore, the government should seize the opportunity, transform function and improve the capacity of governance so as to provide motives for low-carbon economic development.

\section{Relationship between Low-carbon Economy and Transformation of Government Functions}

Low-carbon economy is a gradual developing and mature concept in terms of high carbon economy(Zhang Kunmin, 2008). From the environmentally friendly perspective, it refers to make use of the innovation of technology, and reduce pollutions and the waste of resources, so that promote a green economic growth and the feasible development of society. Functions of government refer to what? An answer is that it means a kind of responsibilities and duties when the administrative organs manage the national and social public affairs according to law (Qian Mengdan, 2010). However, in modern society, the government's economic function is developing unilaterally which bring a lot of new problem, such as environmental problems, energy and resource problems. All of which requires the government to rebalance and position its functions, so as to adapt to the needs for future development (Zhang Kangzhi, 2004). Therefore, what really matters is how to achieve the 
transformation of government functions. Based on the definition of government functions and the perspective of low-carbon economy, the transformation of government functions aims to satisfy the needs of developing the low-carbon economy, focus on optimizing and integrating the present functions which hinder the development of low-carbon economy, and constructs a series of government agencies coordinated with low-carbon development's need.

In fact, the development of low-carbon economy and the transformation of government functions can coexist and additionally promote each other. For example, on the one hand, if the government could cultivate consciousness on the low-carbon economy from the strategic height, then it could advance the function efficiency and self-execution, guide the consumption propensity and lead the development of low-carbon economy with its efficient and saving behaviors. This series of transformation can promote the ability of government for public service, and technical innovation. Objectively, this reform is the essential power for the development of low-carbon economy. On the other hand, the development of low-carbon economy can bring us a healthy and green economic development pattern which contributes to China's long-term development as it can provide necessary material elements and social forces for the transformation of government functions, and bring about a more orderly operating market and a more national consuming society. Meanwhile the process that stimulates the government function more effectively is beneficial for government to deal with the relationship among itself, the market and the society while developing economy so that the further optimization of functions would provide regulation and policy safeguard effectively for low-carbon development, give it a boost and improve the international competitiveness of China's low-carbon economy. Thus it also can accelerate the transformation of government functions in turns.

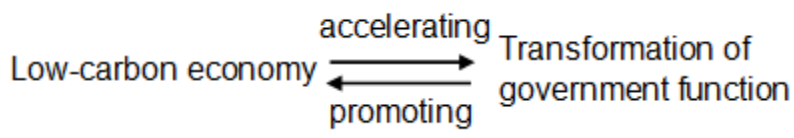

Figure 1. Relationship between low-carbon economy and transformation of government functions

\section{Mode Construction of Government's Functions Transformation from the Low-carbon Perspective}

The key point of transformation of government function is improving its own efficiency of relevant functions and delegate powers, and making market mechanism participate in solving low-carbon problems. So we consider that the transformation of government function is reflected by two dimensions, namely the extent of carbon marketization and implementation efficiency of government functions. The extent of carbon marketization treats "decentralization" as the core, gives full play the role of market in the government's macro-control. The implementation of government function means that the achievement extent of governments functions in the decision-making, implementation, evaluation and other aspects, which is a decisive factor for government function's effect, also the channels for changing some laggard functions. From the Boston Matrix analysis method, with the two dimensions of the extent of low-carbon marketization and the implementation efficiency of government functions, we construct four government function modes from low-carbon economy, the situation of low extent of both low-carbon marketization and implementation of government functions is called "accomplish nothing" function mode. Under the former with low degree and the latter with high degree, is "stick in the mud" function mode. On the contrary, it is the "paper tiger" function mode. Under the both high situation, it is "much to offer" function mode. The government functions can be divided into political function, economic function, cultural function and social function. These four functions have different characteristics in each mode.

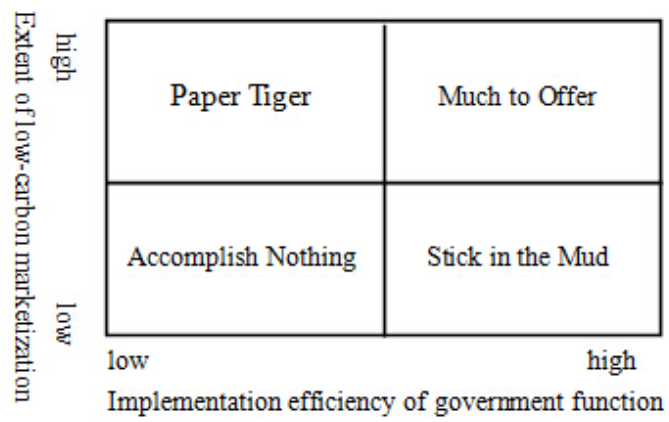

Figure 2. Mode construction of government functions transformation 


\subsection{Political Functions}

The government of "accomplish nothing" mode does not formulate and coordinate the development of low-carbon economy from the whole situation, and lacks the relevant policies to ensure and promote the development of low carbon. What's more, it does not set standard of carbon emission according to the local actual condition and its supervision is poor. The government of "stick in the mud" mode has been doing something useful, and established the various rules and regulations which can promote the development of low-carbon economy. However, it does not open the market actively, and lacks the contact with relevant social organization and professionals. The "paper tiger" mode streamlines administration and delegates power to the lower levels as well as making the market mechanism operate in low-carbon economy. Additionally, it takes advantages of the price and competition mechanism of the market to stimulate vitality in the field of low-carbon natural resources allocation and public facilities construction. However, the government does not take regulatory measures to coordinate the relationship between market and macroeconomic policy. The "much to offer" mode has been taking effective measures for both of itself and the market. It not only values the environmental problems and formulates the low-carbon strategic goal, and then constructs a complete and systemic low-carbon planning, but also pilots low-carbon trading actively and uses the competition mechanism of the market to stimulate the development of low-carbon vitality.

\subsection{Economic Functions}

The government in "accomplish nothing" mode is still according to the economic development pattern of "get-rich-first, clean-up-later", and they strive merely for growth rate of GDP and fiscal revenue, meanwhile the serious destruction of environment by economic development has been ignored. The "stick in the mud" mode has stepped in the energy-saving circular orbit for resource utilization. They gradually weed out the energy-intensive and highly polluting industries. However, the government still holds on the property right of national assets and natural resource, intervenes in the market operations too much and lacks a liberal environment for developing carbon balance transaction mechanism. The "paper tiger" mode has high level of low carbon marketization and its features such as independence property rights, independent management, financially autonomous make low-carbon economy more suitable for public demand, at the same time, they improve the utilization efficiency of resource. Regrettably, government does not take necessary measures to solve the market failures. The government of "much to offer" mode opens the market when performs the relevant functions, and makes the low-carbon fully develop in economic level.

\subsection{Cultural Functions}

Government of "accomplish nothing" mode is lack of low-carbon awareness, without playing a dominant role in improving the public spiritual civilization in whole society. The mass media and social organizations neither guide the public understand low-carbon economy nor cultivate the social cultural atmosphere of low-carbon. "Stick in the mud" mode through various forms of publicity and education activities, cultivates and improves the sense of resources crisis, environment protection and low-carbon economy (Zhang Jian, Zhang Zaisheng, Chen Hongyi, 2011). It sets a good example for public from its own, however, the social subjects do not participate in the construction of low-carbon culture and set up the environment of good low-carbon culture actively. "Paper tiger" mode makes the market play its role more, which lets the public's understanding about the low-carbon culture almost from social spreading. As a result, the government does not play the role of cultural dominance and supervision, and fails to spread scientific low-carbon concept. As the best mode, the government of "much to offer" plays a leading role in fostering the low-carbon behavior patterns, forming the energy-saving lifestyle and building the low-carbon social culture. Meanwhile, social forces cooperate actively with propagandizing advanced concepts of low-carbon and environmental protection consciousness so as to integrate the low-carbon culture in daily life practically.

\subsection{Social Functions}

Government of "accomplish nothing" mode does not change the pattern from "control" to "service" and provide for fundamentally public services about low-carbon are very little. Meanwhile, enterprises, research institutions and colleges extend something about low-carbon economy superficially. Government in "stick in the mud" mode performs its service functions actively, improves the transportation network and the conditions of low carbon travel, but it still lacks the incorporation with market mechanism so that the market has limited effectiveness. "Paper tiger" mode is relying on market mechanism merely and it is short of rigorous standards to evaluate the quality and quantity of public service, which is adverse to low-carbon economy's sustainable and efficient development. Government of "much to offer" mode introduces market mechanism for low-carbon development, and a portion of low carbon public services are outsourced to those social organizations who have favorable 
qualification and ability. Furthermore, it establishes and perfects the legal safeguard mechanism of the circular economy's public participation mechanism, which makes the public participation go to the institutionalization. For example, establishing the environment information disclosing system, environmental public interest litigation system, improving the system of environmental compensation and pollution victims assistance mechanism, etc. (Guo Yaxue, Wei Ran, 2008).

Four modes have different characters on the political, economic, cultural and social functions, which are shown as table 1:

Table 1. Content comparison of four modes

\begin{tabular}{|c|c|c|c|c|}
\hline $\begin{array}{c}\text { Mode } \\
\text { Function }\end{array}$ & $\begin{array}{l}\text { Accomplish } \\
\text { Nothing }\end{array}$ & Stick in the Mud & Paper Tiger & Much to Offer \\
\hline $\begin{array}{l}\text { Political } \\
\text { Function }\end{array}$ & $\begin{array}{c}\text { Lack of relevant } \\
\text { policy }\end{array}$ & Grasp the power alone & Government inaction & Delegate power \\
\hline $\begin{array}{l}\text { Economic } \\
\text { Function }\end{array}$ & Extensive form & Regulated form & Market mechanism & $\begin{array}{l}\text { Government and } \\
\text { market combining }\end{array}$ \\
\hline $\begin{array}{l}\text { Cultural } \\
\text { Function }\end{array}$ & $\begin{array}{c}\text { Lack of low-carbon } \\
\text { Awareness }\end{array}$ & $\begin{array}{l}\text { Government leading } \\
\text { propagandism }\end{array}$ & $\begin{array}{c}\text { Propagating actively of } \\
\text { society }\end{array}$ & $\begin{array}{l}\text { Cultivating social } \\
\text { culture }\end{array}$ \\
\hline $\begin{array}{c}\text { Social } \\
\text { Function }\end{array}$ & $\begin{array}{l}\text { Lack of public } \\
\text { facilities }\end{array}$ & $\begin{array}{l}\text { Performing public } \\
\text { service function }\end{array}$ & $\begin{array}{l}\text { Low-carbon service } \\
\text { provided by society }\end{array}$ & $\begin{array}{c}\text { Multiple } \\
\text { collaborative } \\
\text { participation }\end{array}$ \\
\hline
\end{tabular}

\section{Transformation Path of Government Function's Mode from Low-carbon Economy Perspective}

To achieve the optimum transformation of government functions in the condition of low-carbon economy, the government need seek paths ceaselessly to reach the "much to offer" mode. Each mode can transform from lower level to higher level constantly. "Accomplish nothing" mode, as the lowest level model, will be weeded out from whole pattern if it could not achieve the transformation actively. However, if it transforms the current situation, it can manage to get to "paper tiger" mode or "stick in the mud" mode, which two should take further measures to achieve transformation into "much to offer" mode in order to achieve the optimum transformation itself to the best mode of government function. The specific transformation path is shown in figure 3 .

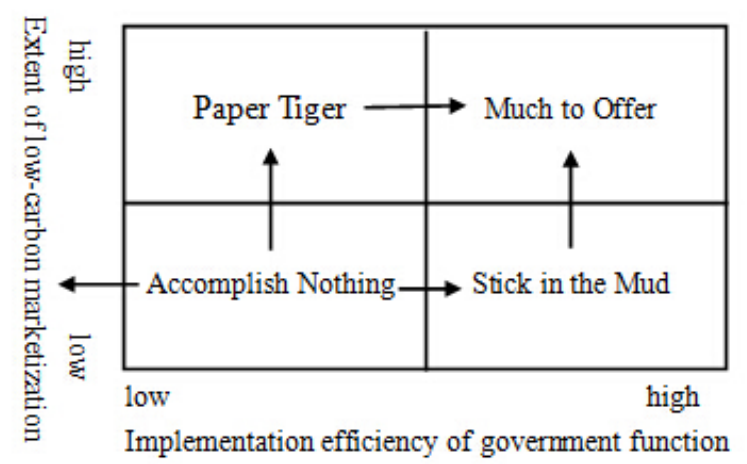

Figure 3. Transformation path of government functions

\subsection{Accomplish Nothing Mode Should Weed Out}

Accomplish nothing mode lies in the lowest level among the four types, and in the low situation of the implementation efficiency of government function and the degree of low-carbon marketization. The government lacks the basic awareness, and doesn't take relevant actions to transform its functions. As a result, the low-carbon development of the whole society doesn't break the ice. Accomplish nothing mode can't achieve 
transformation into the higher function mode and will be cleaned out if the government stands still and refuses to make any progress.

\subsection{Accomplish Nothing Mode Transforms to Stick in the Mud Mode}

To achieve transformation from the accomplish nothing mode to stick in the mud mode which implements the functions effectively, the government needs to make a great shelf-breakthrough. Since the government still grasps the large power, it can impose some important influences on the development of low-carbon economy and reinforce the functions about low-carbon economy through taking the ecology priority as its fundamental values, low-carbon management as its fundamental function, taking the low-carbon economy into state economy and the social development of overall framework. As the direct implementor of policy innovation, government supply system is the most effective method, and the government can take actions to correct the conditions which are resulted from by insufficient institution provision (Wang Weiguang, 2006). The government can formulate policies and regulations, realize the low-carbon development goal measured and exert the leading function of policy and compulsive utility of law. At the same time, it can increase the investment in ecological protection, strengthen the support for reduction and exemption of tax, and provide fiscal subsidies to cleaning production, energy conservation and emission reduction, as well as new technology's research and using (Frédéric Ghersi, 2014).Through various channels, using a variety of methods, the government can raise money for curbing and preventing the pollution effectively.

\subsection{Accomplish Nothing Mode Transforms to Paper Tiger Mode}

Firstly, government plays a main role in making the low-carbon marketization and giving play to the society and public, propelling the low-carbon techniques innovation and researching some advanced technologies about greenhouse gases capture and new energy development so as to form low-carbon high-technology system covering every field gradually. The impacts of media and social organizations should be intensified, which direct customers to conduct energy conservation and emissions reduction. What's more, the government constructs the open market and bulletins the conditions to the society, guarantees the public's rights of knowing and participating. To construct relevant low-carbon feedback mechanism, make enterprises, factories and customers can respond to government performance timely. The paper tiger mode encourages public to provide recommendations, participates in our country's low-carbon construction actively through a variety of internet media channels so as to structure the situation of social multiple subjects governing together.

\subsection{Stick in the Mud Mode Transforms to Much to Offer Mode}

In stick in the mud mode, the government has higher function implementation efficiency in low-carbon development. However, the extent of low-carbon marketization is low and social participation is inadequate. When the government maintains the development of low-carbon economy in China, it also needs to exploit the market which can promote low-carbon development. In order to construct carbon emission trading mechanism and define environment and resources property definitely, the government can try to conduct the low-carbon trade in mature district and construct relevant low-carbon industrial parks, and promote the function transforming to service governing mod from manage governing mode. In the whole system, society participation and market governance ought to be strengthened to achieve diversified governance. Only when the government attracts all kinds of powers to participate in developing low-carbon economy collectively, such as the social group, the public, the academic research institution, enterprises and public unit, can it promote and achieve its own main status better( Zhao Yuan, 2011).

\subsection{Paper Tiger Mode Transforms to Much to Offer Mode}

In the paper tiger mode, the extent of low-carbon marketization is high. Social organizations grow well and multiple subjects participate in it to offer advice and suggestions for ecological and environmental protection from different levels. The core is on the basis of market mechanism, through institutional framework and policy measures, forming clear, stable and long-term guidance and encouragement (Zhang Yipeng, 2009). However, the government only plays the corresponding guiding role, then fails to give full play its own advantages and reaches the final target. For transforming to the much to offer mode, firstly it needs government to propel low-carbon regulations innovation and the use of low-carbon policy tools. Secondly, it can improve the government organizations structure, integrate functions, and coordinate different department and institution's work scientifically. What's more, the communication between the departments ought to be enhanced, which makes every local government condensing together through low-carbon economy and serving for the public existing environment collectively. Above all, the government improves administrative efficiency for low-carbon economy's development and carries out relevant functions actively from macro-level, which can transform to the much to offer mode successfully. 


\section{System Integration of Government Function's Transformation from Low-Carbon Economy Perspective}

For the sake of achieving transformation of government function, the government needs to improve the implementation efficiency of functions and the extent of low-carbon marketization. The interactions between each other, with extra four major elements: government's administrative level, rational allocation of market resources, multiple subjects' participation and low carbon national competitiveness, constitute the government functions transformation system under the low-carbon economy collectively. Every element through mutual connections acts on the government's function transformation, and drives its continuous development. The integrated framework is showed in figure 4 .

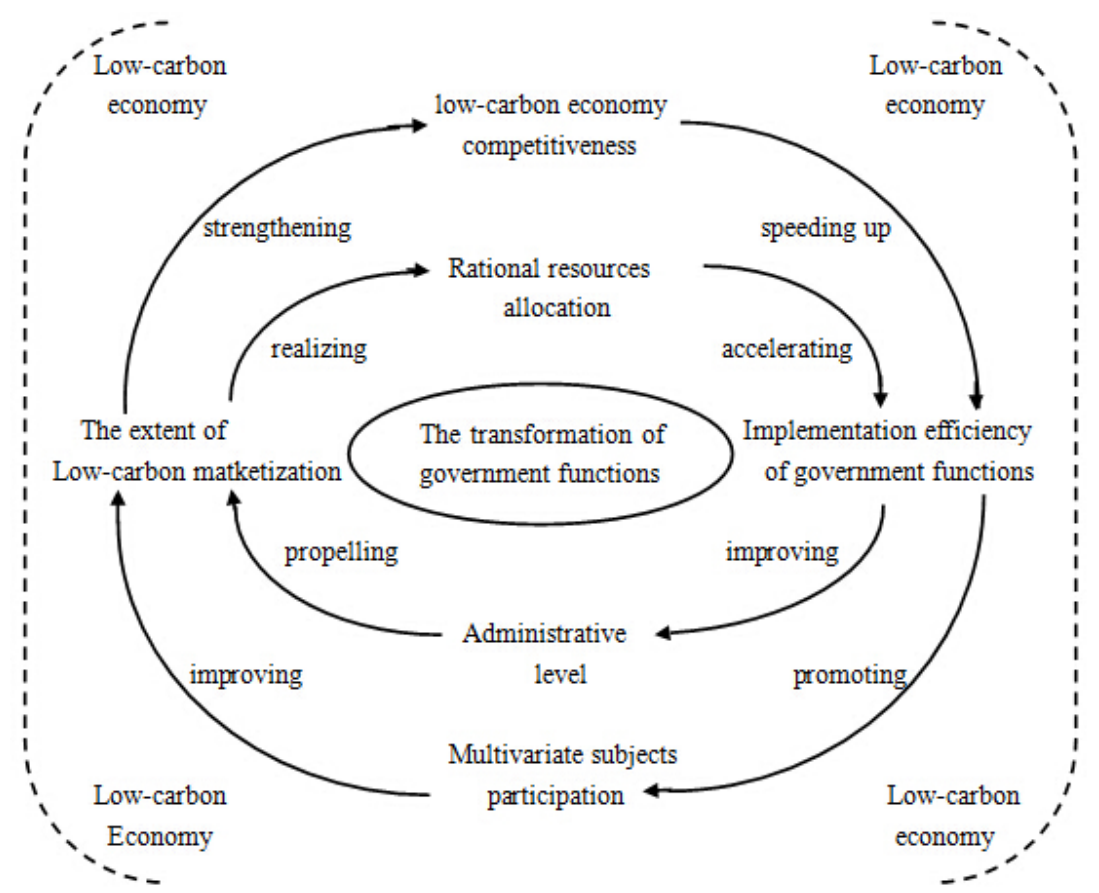

Figure 4. System integration of government's function transformation

Firstly, government can play a major role in promoting its own function implementation efficiency, and improve administrative level by strengthening internal integration. The enhancement of government's market awareness can be helpful to promote market's vitality and propel low-carbon marketization, which can result in more citizens participating in the development of low-carbon economy. Secondly, the low-carbon marketization is improving and market mechanism is playing a role, which promotes some system such as carbon trading, carbon quota, carbon trust fund, so as to achieve rational allocation of social resources effectively from the whole social perspective and get to the Pareto Optimality. The rational allocation of resources makes the whole society full use of resources and reduces the environmental external effect, which further accelerates the implementation functions of government and promotes the transformation of functions. Thirdly, low-carbon marketization releases social vitality and makes government develop a better low-carbon economy in political, economy, social, cultural aspects and enhances the comprehensive national competitiveness of low carbon. The enhancement of national competitiveness of China encourages the government improving functions efficiency as well and creates conditions constantly to promote reform and innovation, which will contributes to huge improvement of function efficiency in return. Only by accelerating these ways, can social multiple subjects participate in environmental governance actively, such as the social organizations, enterprises, and customers, etc. The open participation of social subjects further improves the low-carbon marketization, and then boosts the functions transformation of government directly.

\section{Policy Suggestions on Transforming Governmental Function from the Perspective of Low-carbon Economy}

\subsection{Cultivating Low-carbon Development Awareness, Setting up the Environmental Targets}


In the first place, the government should aware the seriousness of environmental problems, cultivate low-carbon consciousness actively and strengthen ecological concept. Making the low-carbon economy's plan in stages, the government ought to try its best to pursue the harmonious existence between human and nature, insist on sustainable development. The overall environmental aim made by China government is to drop the energy intensity of GDP to 2.25 tons of standard coal per million yuan, improve energy saving rate $3 \%$ while maintain at least $2.3 \%$ per year during the year of 2011 to the year of 2020, and keep the energy intensity level at 1.54 tons of standard coal per million yuan in 2020 (Xing Jijun, Zhao Gang, 2007). Therefore, in the process of planning and deciding, the government needs to balance the relationship between the growth of GDP and the protection of environment. For example, Quanzhou has started the work about compensation for the use of emission rights and carbon trading pilot, and put the emission reductions formed by the centralized treatment facilities of water pollution into reserve transaction category. And the government strives to fully implement the action in all industrial pollution emission firms in 2016. Encouraging enterprises to achieve a low-carbon production and enhancing social responsibility of corporations, the administration should urge them to set target consciously and implement measures about mitigation of the carbon emissions. What's more, the government need foster social organizations, and inspire them with low-carbon concept, meanwhile, the social organizations should undertake parts of the responsibilities to propaganda and guide the public which aim at helping people set goals about green living in their daily lives, encourage healthy, green consuming concepts.

\subsection{Completing the Laws and Regulations, Constructing the System of Synergetic Governance}

The government is given priority to break through the original system constraints to and rebuild the perfect law system. From the basic system, regulatory system to incentive system, assessment system, the wide coverage is used to spur and motivate relevant behaviors accordingly. Furthermore, it need to promote various powers involving the government, enterprises, associations, companies, scientific institution and medias to take part and cooperate in the process, boosting the low-carbon economy development jointly (Li Junpeng, 2010). At the same time, it's high time to open the market and releases the social vitality, which can make itself, the market, and the society form collaborative governance, building effective governance system, and enhancing intrinsic motivation of overall energy saving.

\subsection{Leading the Transformation of Industrial Structure, Promoting the Use of Clean Energy}

The key point of the development of low-carbon economy is a thorough governance from the industrial structure, optimizing the industrial layout overall. The government should lead to upgrade the traditional high energy consumption, high pollution industry, to build low-carbon industries, which can make the industrial structure upgrade to agriculture, industry, services co-leading model of economic development instead of traditional model driven mainly by industry to lead economic growth. At the same time, it advocates the steady development of the primary industry, expands the scale of the second industrial, and gives the priority to the third industry of low pollution and high efficiency(Wu Qian, 2013). So the government should strive to spread the use of clean energy, support the development of low-carbon industries and green products, promote the purchase of energy-saving and environmental protection material, as well as the energy-saving equipment and low-carbon products. It's also very important to put the energy diversification strategy into effect, developing clean energy sources and energy conservation and environmental protection industry, such as wind power, nuclear power, hydropower, solar power etc., and promoting distributed energy sources and develop smart power grid, so that the proportion of coal can be cut down gradually.

\subsection{Creating Social Low-carbon Atmosphere and the Culture of Energy Conservation and Environmental Protection}

The government transforms its functions so as to give the society more autonomy. According to the measured data, the energy consumption of urban residents had accounted $26 \%$ of the national energy consumption, about $30 \%$ caused by their living actions and the need for these actions. (Chen Xiaochun, Zhang Xihui, 2009). The relevant social organizations and medias play their important roles, spreading the knowledge concerning resources conservation, environmental protection and other issues to the public by network, television, newspapers, etc, to improve the attention of citizens for the low-carbon economy. They set up public's low-carbon ideas and create an atmosphere of low-carbon development in the whole society. In addition, the government promotes enterprise engaged in the low-carbon production, and low-carbon management through the market mechanism, which aims at forming the low-carbon corporate culture for their long-term developments. Besides, they should cultivate the public's sense of crisis, making them recognize the enormous damages brought to our country by the greenhouse effect, and inspiring them, finally, internalizing low-carbon actions as conscious behavior, that is to form the ecological values and low carbon consumption, so that the whole society 
can be filled with the excellent low-carbon awareness from top to bottom.

\subsection{Perfecting the Government Assessment Mechanism, Standardizing the Ecological Management and Operation}

In order to regulate the behavior of the government and encourage it to take actions, firstly, the evaluation mechanism for government should be improved. That is to put the "low-carbon economy" performance in the government performance evaluation indicators and makes it supervised by the third party organizations and citizens. Only the government wins the public credibility and executive force, can it promote the exercise of ecological functions more effectively and, promotes the every work operation of carbon economy. The government should establish reasonable ecological compensation mechanism, set up ecological protection standards by region, and improve the ecological environment monitoring system, which is in order to provide guarantees for ecological governance operation. What's more, strengthening the responsibility, the government can decompose specific target indicators of emission reduction to each area, blaming the area that cannot complete the task on time or cannot complete the task totally. The more strict energy efficiency standards, low-carbon commodity standards should be formulated, strengthening efficiency standards and labeling, and implementing energy audit and certification (Zhang Lun, Fu Lin, 2012). The administration should take strict enforcement of illegal carbon emissions, excessive carbon emissions, evading monitoring and other acts, increasing the punishment, furthermore, the relevant persons in charge should be educated and persuaded.

\section{Conclusion}

This article is based on the low-carbon economy perspective, adopting a new perspective, namely through mode construction, path transformation systems integration (M-P-I paradigm), to research the measures promoting the transformation of government functions. We choose two representative dimension, the extent of carbon marketization and the implementation efficiency of the government functions, which are both divided into high and low two dimensions, proposing that the transformation of government functions can be constructed of four modes, accomplish nothing type functions mode, stick in the mud type function mode, paper tiger type function mode, much to offer type function mode. Under each mode, we discuss the specific government functions of each mode in politic, economy, society, culture, respectively, and analyze the path for low mode transforming to the high mode, namely no matter which mode the government functions lies, as long as it continues to create the conditions, to seek the path, to identify strategies, and finally it can convert to the much to offer type mode, so it can achieve the best mode transformation of government functions under the low-carbon economy. Finally, the system is integrated, we gather various factors affecting transformation of government functions to constitute a system, and explore the relationship between the elements and what role it should play. Through exploring the transformation of government functions from low-carbon perspective, the paper aims at finding the solution for government corresponding to the actual situation in the development mode constructed by two different dimensions, and provides the policy basis and specific decisions reference.

\section{Acknowledgments}

This paper is supported by China Scholarship Council Foundation; National Social Science Foundation for Youth of China (11CGL104); Social Science Foundation for Youth of Education Ministry of China (10XJC630009); Major Decision and Consulting Research Foundation of Chongqing (ZDKTB120101); Doctoral Foundation of Southwest University (2012). I appreciate the support and encouragement of these scientific research projects.

\section{References}

Chen, X. C., \& Zhang, X. H. (2009). Brief talk of the consumption guidance under low-carbon. Consumption economy, 11, 71-74.

Chinese Communist Part. (2013). The Third Plenary Session of the eighteen Communist Party of Chinese Bulletin (Full Text). Retrieved from http:/news.xinhuanet.com

Frédéric, G. (2014). Low-Carbon Policy Making vs. Low-Carbon Policy Modeling: State - of- the- Art and Challenges. Environ Model Assess, 19, 345-360. http://dx.doi.org/10.1007/s10666-013-9394-y

Fujian Provincial Government Network. (2014). The opinions about Fujian Provincial People's Government on the promotion of the right to compensation for the use of sewage and transaction work (Trial). Retrieved from http://www.fujian.gov.cn

Guo, Y. W. (2008). Brief review of the development of circular economy and the transformation of government 
functions. East China Economic Management, 22(2), 55-57.

Li, J. P. (2010). Government management innovation facing to low-carbon economy. Leadership Science, 10, 4-6.

Li, K. (2014). The new approach for energy emissions out to do "subtraction" and economic development do "addition". Retrieved from http://news.xinhuanet.com

Qian, M. (2010). Government functions in the context of low-carbon economy. Exchange platform, 7, 55-57.

Wang, W. G. (2006). Self-dependent innovation, industrial development and public policy: A perspective based on government functions. Beijing: economy and management press.

$\mathrm{Wu}$, Q. (2013). Research on path selection of China's low carbon economy. Industrial Economics, 12, 1-3.

Wu, W. Z., Sun, X. Y., \& Liu, Y. (2013, January 13). What's wrong with our air? People's Daily, p. 04.

Xing, J. J., \& Zhao, G. (2007). China should vigorously develop low-carbon economy. China Science and Technology Forum, 10, 87-92.

Zhang, J., Zhang, Z. S., \& Chen, H. Y. (2011). The analysis of low-carbon economy and government function. Journal of Northeastern University, 13(1), 39-41.

Zhang, K. Z. (2004). Philosophy and ethics in public administration. Beijing: Chinese people press.

Zhang, K. M. (2008). Low-carbon world in China: status, challenges and strategies. China Population Resources and Environment, 18(3), 1-7.

Zhang, L., \& Fu, L. (2012). Countermeasure analysis of public service-oriented government function constructing on Heilongjiang province under the background of low-carbon economy. Business Economics, $11,12-15$.

Zhang, Y. P. (2009). Low-carbon economy and low-carbon life. Sino-Global Energy, 14, 46.

Zhao, Y. (2011). Analysis of the role of government in the process of low-carbon economy Chinese. Chinese administration, 8, 96-99.

Wang, W. G. (2006). Self-dependent innovation, industrial development and public policy: A perspective based on government functions. Beijing: Economy and management press.

\section{Copyrights}

Copyright for this article is retained by the author(s), with first publication rights granted to the journal.

This is an open-access article distributed under the terms and conditions of the Creative Commons Attribution license (http://creativecommons.org/licenses/by/3.0/). 